\title{
Balanced Anaesthetic Approach in a Late-Term Gravid Cow Undergoing Metacarpal Fracture Repair
}

\author{
Olga Martin Jurado, ${ }^{1}$ Rahel Jud, ${ }^{1}$ Evelyne Muggli, ${ }^{2}$ and Regula Bettschart-Wolfensberger1 \\ ${ }^{1}$ Section of Anaesthesiology, Clinic for Horses, Vetsuisse Faculty, University of Zurich, 8057 Zurich, Switzerland \\ ${ }^{2}$ Department of Farm Animals, Clinic for Ruminants, Vetsuisse Faculty, University of Zurich, 8057 Zurich, Switzerland
}

Correspondence should be addressed to Olga Martin Jurado, omartinjurado@yahoo.es

Received 3 October 2011; Accepted 17 November 2011

Academic Editors: K. Hittmair, F. Mutinelli, J. Orós, and D. M. Wong

Copyright ( 2011 Olga Martin Jurado et al. This is an open access article distributed under the Creative Commons Attribution License, which permits unrestricted use, distribution, and reproduction in any medium, provided the original work is properly cited.

\begin{abstract}
An $800 \mathrm{~kg}$ Swiss cow, eighth months gravid, was presented for anaesthesia to repair metacarpal fracture. The cow was premedicated with intravenous isoxsuprine, butorphanol, ketoprofen, and xylazine IM and induced with ketamine and diazepam IV. In lateral recumbency, the trachea was intubated, and isoflurane in oxygen and air was administered. Despite a ring block with lidocaine, purposeful movement happened, and xylazine $0.02 \mathrm{mg} \mathrm{kg}^{-1} \mathrm{~h}^{-1}$ and ketamine $0.6 \mathrm{mg} \mathrm{kg}^{-1} \mathrm{~h}^{-1}$ constant rate infusion was started. During anaesthesia, slight hypercapnia and hypoxaemia developed. Total time of xylazine and ketamine infusion was 3.5 hours. Total anaesthesia time was 4.5 hours. For recovery of anaesthesia, isoflurane was discontinued, and in sternal recumbency, the trachea was extubated when the cow swallowed. Paralysis of the left radial nerve occurred, and the cow was supported to stand up after 2 hours. The radial nerve paralysis resolved within three days. A healthy calf was born at term. This is the first paper that describes the successful use of adjunctive xylazine and ketamine infusion to isoflurane anaesthesia in a late-term gravid cow undergoing fracture repair during 4.5 hours.
\end{abstract}

\section{Introduction}

In the present paper, a late-term gravid cow needed anaesthesia for fracture repair. The main anaesthetic concerns in this particular case were impaired respiratory and cardiovascular function due to anaesthetics, increased intra-abdominal pressure and long recumbency, severe pain, and danger of regurgitation during anaesthesia induction as well as risk of abortion following anaesthesia.

To maintain anaesthesia for several hours in a cow, isoflurane is the drug of choice. It is minimally metabolized, and therefore, recovery should be prompt, and judgement of the state of hypnosis during anaesthesia is easily performed [1]. However, it is a weak analgesic, and respiration as well as cardiovascular function is depressed dosedependently [2].

In other species, the use of constant rate infusions of different drugs in order to maintain balanced anaesthesia for longer and more complicated surgeries is common practice. The amount of inhalation anaesthetics necessary to maintain anaesthesia is thereby reduced and cardiopulmonary function is improved $[2,3]$.
Alpha-2 adrenergic agonists provide sedation, analgesia and reduce minimal anaesthetic concentration (MAC) dosedependently [4]. Following bolus administration, they induce bradycardia and hypertension followed by hypotension. However, during constant rate infusion (CRI) at steady state, the cardiovascular effects are minimized [5]. In horses, alpha-2 adrenergic agonists in combination with isoflurane have resulted in similar cardiovascular function as their combinations with other balanced anaesthetic regimes such as ketamine and midazolam [2].

Ketamine is a dissociative general anaesthetic and analgesic that reduces MAC via inhibition of $\mathrm{N}$-methyl D-aspartate receptors. Via sympathetic activation, it increases heart rate and arterial blood pressures [1]. Therefore, it seems to be an ideal drug to be used in combination with alpha-2 adrenergic agonists.

The present case describes the anaesthetic procedure in a cow with metacarpal fracture in which analgesia with butorphanol, ketoprofen, and a local block was insufficient to perform surgery under isoflurane anaesthesia. Additional 
continuous administration of xylazine and ketamine provided appropriate depth of anaesthesia and adequate analgesia.

\section{Case Description}

A 5-year-old female brown Swiss cow in the eighth month of gravidity and weighing $800 \mathrm{~kg}$ was presented to the Veterinary Hospital with a closed comminuted metacarpal fracture. During transport and diagnostic examination, the cow was fasted. Before anaesthesia, the cow was overall deprived of food and water for $10 \mathrm{~h}$.

On admission, the right jugular vein of the cow was catheterized using a 14 gauge over-needle central venous catheter (Becton Dickson, Yishun, Singapore). Fluid therapy was started 4 hours before premedication using lactated Ringer's solution at $3 \mathrm{ml} \mathrm{kg}^{-1} \mathrm{~h}^{-1}$ (Fresenius Kabi AG, Stans, Switzerland).

Before premedication, heart rate (HR) was 90 beats $\min ^{-1}$, respiratory rate (RR) 36 breaths $\mathrm{min}^{-1}$, and rectal temperature $38.2^{\circ} \mathrm{C}$. Otherwise, complementary examinations did not reveal any abnormalities.

For premedication, the cow received tetanus serum 10000 UI IM (Intervet, Veterinaria AG, Zurich, Switzerland), isoxsuprine $0.25 \mathrm{mg} \mathrm{kg}^{-1}$ IV (Degraspasmin, Dr. E. Graeub AG, Bern, Switzerland), penicillin $30000 \mathrm{UI} \mathrm{kg}^{-1} \mathrm{IV}$ (Streuli Pharma AG, Uznach, Switzerland), gentamicin $4 \mathrm{mg} \mathrm{kg}^{-1}$ IV (Vetagent, Veterinaria AG, Zurich, Switzerland), butorphanol $0.01 \mathrm{mg} \mathrm{kg}^{-1}$ IV (Morphasol 4, Dr. E. Graeub AG, Bern, Switzerland), ketoprofen $3 \mathrm{mg} \mathrm{kg}^{-1}$ IV (Rifen, Streuli Pharma AG, Uznach, Switzerland), and xylazine $0.1 \mathrm{mg} \mathrm{kg}^{-1}$ IM (Rompun 2\%, Streuli Pharma AG, Uznach, Switzerland). Isoxsuprine, a beta-adrenergic agonist which causes direct relaxation of uterine and vascular smooth muscle, was used to minimize the risk of abortion [6].

Twenty minutes after xylazine, induction of anaesthesia was performed with ketamine $2 \mathrm{mg} \mathrm{kg}^{-1}$ IV (Narketan, Dr. E. Graeub AG, Bern, Switzerland) and diazepam $0.02 \mathrm{mg} \mathrm{kg}^{-1}$ IV (Valium, Roche Pharma, Reinach, Switzerland).

As soon as the cow reached lateral recumbency, a $30 \mathrm{~mm}$ low-pressure, high-volume cuffed endotracheal tube (Surgivet, Smith Medical Pm Inc., WI, USA) was advanced into the trachea following digital palpation of the epiglottis and arytenoid cartilages. For surgery, the cow was positioned in left lateral recumbency on a smooth, padded table with the head positioned allowing drainage of saliva. Maintenance of anaesthesia was performed with isoflurane (Provet AG, Lyssach, Switzerland) in oxygen $\left(4 \mathrm{~L} \mathrm{~min}^{-1}\right)$ and air $\left(1.5 \mathrm{~L} \mathrm{~min}^{-1}\right)$ delivered by a large animal anaesthesia machine (Provet AG, Lyssach, Switzerland). The cow was allowed to breathe spontaneously. The isoflurane concentration was set to maintain a sluggish palpebral reflex.

During anaesthesia, the cow received $10 \mathrm{~mL} \mathrm{~kg}^{-1} \mathrm{~h}^{-1}$ lactated Ringer's solution together with a total of 3 liters hetastarch $10 \%$ solution $\left(2 \mathrm{~mL} \mathrm{~kg}^{-1} \mathrm{~h}^{-1}\right.$, Fresenius kabi AG, Stans, Switzerland). Isoxsuprine was repeatedly administered every 2 hours during anaesthesia.

Monitoring of cardiopulmonary function consisted of constant observation of a 3 lead ECG (Carbamed, Liebefeld,
Switzerland), intra-arterial blood pressures via a 22-gauge catheter (Terumo, Leuven, Belgium) in the auricular artery connected to a pressure transducer located at the level of the heart and to a monitor (Datex Ohmeda, capnomac ultima, Helsinki, Finland) and the fractions of inspired and expired gases (Datex Ohmeda, capnomac ultima, Helsinki, Finland). Pulse oximetry was attempted on the tongue using a clip probe (Ohmeda Biox, CO, USA), but no valid measurements could be obtained due to poor signal. The parameters recorded every five minutes were heart rate (HR), respiratory rate (RR), systolic (SAP), mean (MAP) and diastolic arterial blood pressures (DAP), end tidal carbon dioxide $\left(\mathrm{EtCO}_{2}\right)$, and the inspired oxygen fraction $\left(\mathrm{FiO}_{2}\right)$. The gas monitor used is not able to differentiate between methane and isoflurane; therefore, the end tidal concentration of isoflurane could not be accurately measured and will not be mentioned further.

An arterial blood sample for blood gas analysis was obtained every hour during anaesthesia, and it was immediately analyzed with a point of care i-stat device (Axonlab, The Hague, The Netherlands). The first arterial blood sample was obtained 60 minutes after induction of anaesthesia.

Following positioning, a ring block using $10 \mathrm{~mL}$ of $2 \%$ lidocaine (Astra Zeneca, Zug, Switzerland) was performed at the proximal metacarpal level to block the ulnar, radial, and median nerves. Twenty minutes later, although depth of anaesthesia seemed appropriate (sluggish palpebral reflex, HR 95 beats $\mathrm{min}^{-1}$, MAP $70 \mathrm{mmHg}$ and regular stable respiratory rate of 30 breaths $\mathrm{min}^{-1}$ ), a slight retraction of the fractured leg was observed when surgical field preparation started. This fact was interpreted as a lack of analgesia. Therefore, a constant rate infusion of xylazine $0.02 \mathrm{mg} \mathrm{kg}^{-1} \mathrm{~h}^{-1}$ and ketamine $0.6 \mathrm{mg} \mathrm{kg}^{-1} \mathrm{~h}^{-1}$ administered each with a syringe pump (Syramed, Arcomed AG, Regensdorf, Switzerland) was started.

For the remaining anaesthesia, vaporizer settings of $1.5 \%$ isoflurane for the first hour and of $1 \%-1.3 \%$ for the following hours were set with a flow rate of $4 \mathrm{~L} \mathrm{~min}^{-1}$ oxygen and $1.5 \mathrm{~L} \mathrm{~min}^{-1}$ air. This together with the xylazine and the ketamine CRI resulted in sufficient depth of anaesthesia preventing any further movement.

Throughout anaesthesia, the cow maintained spontaneous breathing at a rate of $28-32$ breaths $\mathrm{min}^{-1}$. Results of arterial blood gases are shown in Table 1. Progressive hypoxaemia occurred reaching a minimum $\mathrm{PaO}_{2}$ of $6.4 \mathrm{kPa}$ $(48 \mathrm{mmHg}) 4$ hours after anaesthesia induction. An average $\mathrm{FiO}_{2}$ of 0.6 was administered during the procedure.

Heart rate and mean arterial blood pressure during maintenance of anaesthesia are presented in Figure 1. After starting the CRIs, MAP was stable between 90 and $100 \mathrm{mmHg}$ for 3 hours after which it increased to reach a maximum of $122 \mathrm{mmHg}$ at the end of anaesthesia. HR decreased progressively over time; 3 hours after anaesthesia induction, HR reached a minimum of 58 beats $\mathrm{min}^{-1}$, remaining stable thereafter.

The CRI of ketamine and xylazine was stopped 30 minutes before the end of anaesthesia was presumed. In total, the CRI was administered during 210 minutes. 
TABLE 1: Arterial blood samples from a late-term gravid cow undergoing metacarpal fracture repair. The first sample (T1) corresponds to $1 \mathrm{~h}$ after induction of anaesthesia; T2, T3, and T4 to successive hours.

\begin{tabular}{|c|c|c|c|c|c|c|}
\hline & $\mathrm{pH}$ & $\mathrm{PaCO}_{2} \mathrm{kPa}(\mathrm{mmHg})$ & $\mathrm{PaO}_{2} \mathrm{kPa}(\mathrm{mmHg})$ & $\mathrm{HCO}_{3}{ }^{-} \mathrm{mmol} \mathrm{L}^{-1}$ & $\mathrm{BE} \mathrm{mmol} \mathrm{L}-1$ & $\mathrm{SO}_{2} \%$ \\
\hline $\mathrm{T} 1$ & 7.35 & $6.5(49)$ & $8.5(64)$ & 27.8 & 2 & 91 \\
\hline $\mathrm{T} 2$ & 7.34 & $6.4(48)$ & $9.7(73)$ & 25.5 & 2 & 93 \\
\hline T3 & 7.33 & $7.3(55)$ & $6.6(50)$ & 28 & 3 & 82 \\
\hline $\mathrm{T} 4$ & 7.35 & $6.0(45)$ & $6.4(48)$ & 25.6 & 2 & 82 \\
\hline
\end{tabular}

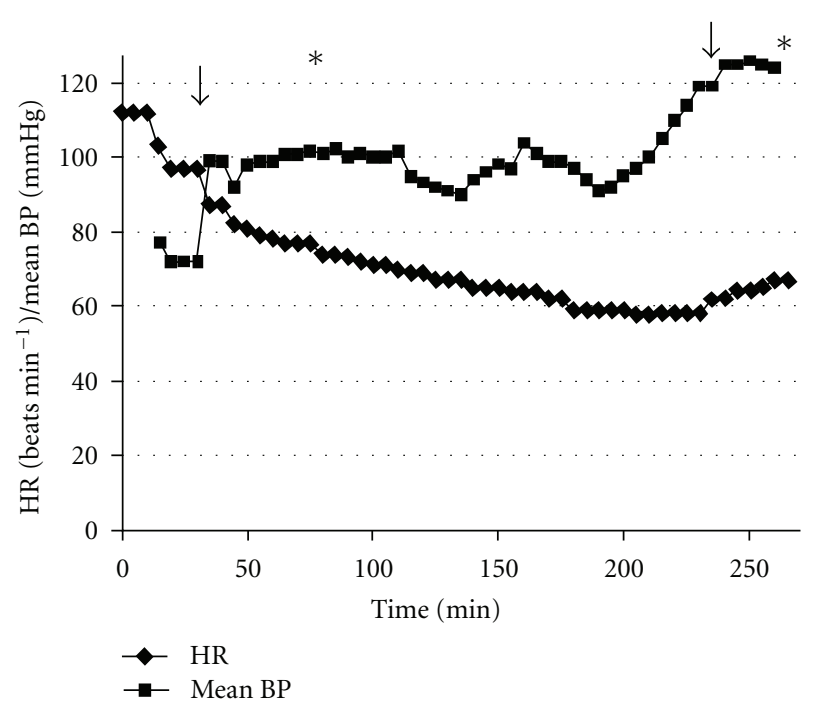

Figure 1: Invasive mean arterial blood pressure (mean BP, mmHg) and heart rate (HR, beats $\mathrm{min}^{-1}$ ) during maintenance of anaesthesia of a gravid cow undergoing metacarpal fracture repair. Arrows correspond to the beginning and end of the constant rate infusion of ketamine $\left(0.6 \mathrm{mg} \mathrm{kg}^{-1} \mathrm{~h}^{-1}\right)$ and xylazine $\left(0.02 \mathrm{mg} \mathrm{kg}^{-1} \mathrm{~h}^{-1}\right)$. Asterisk $(*)$ corresponds to the beginning and the end of the surgery.

Following cast bandage, inhalant anaesthesia was discontinued. Total anaesthesia time was 4.5 hours. No signs of regurgitation or rumen tympani were observed.

For recovery of anaesthesia, the cow was positioned in sternal recumbency on the floor of the operation theatre. Twenty minutes after discontinuation of isoflurane anaesthesia, the cow swallowed, and the endotracheal tube was removed. After 2 hours, the cow was supported to reach standing position and was led to the pen. As a paralysis of the radial nerve of the leg contralateral leg was present, this leg had to be splinted for 3 days. For one week after surgery, the cow needed support to stand up.

Postoperative medical care consisted of fluid therapy with crystalloids as well as antiphlogistic therapy with ketoprofen $3 \mathrm{mg} \mathrm{kg}^{-1}$ SID during the next three days and penicillin $30000 \mathrm{IU} \mathrm{kg}^{-1} \mathrm{TID}$ and gentamicin $4 \mathrm{mg} \mathrm{kg}^{-1}$ SID during the following ten days. The cow stayed at the hospital for radiographic examination and cast exchange. A healthy calf was born at term 1 month after the anaesthetic procedure. As the cow was often laying down, it developed decubital ulcers at different sites during this period, which where locally treated with antiseptic ointment (Bepanthen. Roche, Basel,
Switzerland) and bandages. The cow was discharged with a splint bandage on the fractured leg 10 days after giving birth.

\section{Discussion}

The present case describes the successful anaesthetic management of a late-term gravid cow for fracture repair. Multimodal analgesia including a nonsteroidal anti-inflammatory drug, an opioid and local anaesthesia together with isoflurane were insufficient to prevent the cow from moving when first stimulated. Thus, a constant rate infusion of xylazine and ketamine were additionally started.

This cow was considered a high-risk anaesthesia patient because of the heavy weight, the late-term gravidity, and the expected long duration of anaesthesia. In order to optimize cardiopulmonary function, we aimed at reducing the amount of inhalant agents from the beginning of anaesthesia. For this, the use of local anaesthesia as an adjuvant to inhalation anaesthetics is theoretically the best option, as complete blockade of nociception should occur without impairment of cardiopulmonary function. The ring blockade in the present case was apparently not efficient. Enough time was given for effect onset, but the cow was still moving following stimulation. The conduction blockade produced by lidocaine may have been impaired due to the acidic tissue environment in the fractured leg [7] or inappropriate technique.

We chose to adjunctively administer xylazine in combination with ketamine, as it seems to be an ideal combination. The reduction of sympathetic tone produced by xylazine is outweighed by the sympathetic stimulatory effect of ketamine [2]. As both drugs exert their analgesic effects through different mechanisms, analgesia might be optimized $[8,9]$. In horses, the constant intravenous administration of ketamine at a subanaesthetic dose $\left(1.2 \mathrm{mg} \mathrm{kg}^{-1} \mathrm{~h}^{-1}\right)$ and the single bolus administration of xylazine $\left(1.0 \mathrm{mg} \mathrm{kg}^{-1} \mathrm{IV}\right)$ were shown to be antinociceptive to $[8,9]$. In ruminants, a combination of only xylazine and ketamine with or without a centrally acting muscle relaxant was successfully used to provide surgical anaesthesia with minimal cardiorespiratory depression [10-12]. However, in this case, the only use of xylazine and ketamine was not an option due to two major reasons. On one hand, following long-term administration of high doses of ketamine, norketamine may accumulate, leading to psychomimetic emergence reactions during recovery of anaesthesia [13]. At the low-dose rate of ketamine used, no apparent side effects were noted during recovery. 
On the other hand, the cow was gravid and would not have benefited from high doses of alpha-2 adrenergic agonists. Xylazine has been shown to increase uterine motility, precipitating an early parturition when administered within the third trimester of gravidity [10]. Moreover, in pregnant cows in late gestation, the administration of xylazine IV was shown to decrease uterine arterial blood flow, increase uterine vascular resistance and $\mathrm{PCO}_{2}$, and reduce oxygen delivery and $\mathrm{PaO}_{2}$ of the foetus [14]. Nevertheless, we chose to use this drug intramuscularly for induction of anaesthesia, as the only use of ketamine and a muscle relaxant was considered inappropriate in a cow weighing $800 \mathrm{~kg}$. We did not consider the constant intraoperative use of xylazine as additive to the risk, as constant alpha- 2 adrenergic agonist plasma levels have been shown to induce only mild cardiopulmonary effects [5]. Detomidine, another alpha-2 adrenergic agonist, has been shown to have a minimal effect on uterine contraction [15]. As detomidine was currently not available in the clinic, xylazine was the only legal alternative to be used. Nonetheless, to minimize the risk of spontaneous abortion in the present case, the smooth muscles of the uterus were successfully relaxed with isoxsuprine, and a healthy calf was born at term.

The dose rates used for xylazine and ketamine CRI were chosen on the basis of extrapolations from other species and the dose rates used in ruminants and their approximate duration of action.

The maintenance of good cardiovascular function in our case was one of the main concerns. With no apparent blood loss, the administration of lactated Ringer's solution at the dose rate of $10 \mathrm{~mL} \mathrm{~kg}^{-1} \mathrm{~h}^{-1}$ in combination with $2 \mathrm{~mL} \mathrm{~kg}^{-1} \mathrm{~h}^{-1}$ Hetastarch seemed sufficient to maintain blood volume. Arterial blood pressures were well maintained and no signs of cardiovascular instability were apparent. Why mean arterial blood pressure started to increase from $90 \mathrm{mmHg}$ to $125 \mathrm{mmHg}$ three hours after the beginning of anaesthesia, whilst the heart rate was stable, is not known. Maybe the infusion therapy was too aggressive or an increase in systemic vascular resistance led to the increase in MAP. An increase in sympathetic stimulation, either caused by pain or ketamine seems unlikely, as the heart rate only increased minimally at the very end of anaesthesia when the CRIs of ketamine and xylazine were switched off. Hypoxaemia could be another reason for an increase in sympathetic stimulation.

The increased intra-abdominal pressure caused by lateterm gravidity and ingesta certainly impaired venous return and interfered with diaphragmatic excursion [7]. In order not to further negatively influence venous return and thus cardiac output and oxygen delivery, the cow was not artificially ventilated. Values of $\mathrm{PaCO}_{2}$ up to $8.9 \mathrm{kPa}$ $(67 \mathrm{mmHg})$ and $9.6 \mathrm{kPa}(72 \mathrm{mmHg})$ after 60 and $90 \mathrm{~min}$ of anaesthesia induction were described in fasted cows anaesthetized with halothane [16]. With the regime used in our case, it was possible to reduce the amount of isoflurane necessary for maintenance of anaesthesia, which lead to such an extent, that only minimal hypoventilation occurred. However, venous admixture was present from the start of anaesthesia, leading to aggravating hypoxaemia with anaesthesia duration. The hypoxaemia was mainly caused by ventilation-perfusion mismatch, and even though it would have probably not benefited from artificial ventilation, an increase of $\mathrm{FiO}_{2}$ to 1 could have helped to improve oxygenation.

The postanaesthetic neuropathy syndrome has been extensively investigated in large animals. From the many contributing factors, the most important is the body position in lateral recumbency [17], high intracompartmental muscle pressure and low arterial blood pressure and insufficient blood supply [18-20], venous stasis [21, 22], and length of procedure $[17,18]$. The cow reported here was $800 \mathrm{~kg}$ and was placed in lateral recumbency for a long period (4.5 hours). The limb contralateral to the fractured limb was fixed to the front end of the table to allow optimal access to the fracture site. The positioning of the limb together with the prolonged recumbency led to a compression of the radial nerve and the arteria axillaris. Local tissue blood supply was impaired, and as its result, the radial nerve was paralysed. Another potential complication of general anaesthesia is postanesthetic myopathy [23]. It has been attributed to ischemic muscle damage secondary to inadequate blood pressure and blood flow during recumbency. In horses, studies show that microvascular and global muscle blood flow is relatively well maintained during isoflurane anesthesia compared to halothane [23]. It is more likely that radial nerve paralysis was the reason for the inability to bare weight after anesthesia, as there was evident local compression of the radial nerve.

\section{Conclusion}

Xylazine $0.02 \mathrm{mg} \mathrm{kg}^{-1} \mathrm{~h}^{-1}$ in combination with ketamine $0.6 \mathrm{mg} \mathrm{kg}^{-1} \mathrm{~h}^{-1}$ was an adequate analgesic adjuvant to isoflurane anaesthesia in a late-term gravid cow undergoing fracture repair. The radial nerve paralysis following surgery was probably a result of the heavy weight of the cow, slightly suboptimal positioning of the affected limb, and the long anaesthesia duration.

\section{Acknowledgment}

The authors would like to thank Professor Karl Nuss for allowing the publication of these data.

\section{References}

[1] T. W. Riebold, "Ruminants," in Veterinary Anesthesia, W. J. Tranquilli, J. C. Thurmon, and K. A. Grimm, Eds., p. 734, Wiley-Blackwell, Baltimore, Md, USA, 2007.

[2] K. Yamashita and W. Muir, "Intravenous anesthetic and analgesic adjuncts to inhalation anesthesia," in Equine Anesthesia: Monitoring and Emergency Therapy, W. Muir and J. A. Hubbel, Eds., pp. 260-276, Elsevier, St. Louis, Mo, USA, 2009.

[3] B. Hansen, "Analgesia for the critically Ill dog or cat: an update," Veterinary Clinics of North America-Small Animal Practice, vol. 38, no. 6, pp. 1353-1363, 2008.

[4] M. D. Sinclair, "A review of the physiological effects of $\alpha 2$ agonists related to the clinical use of medetomidine in small animal practice," Canadian Veterinary Journal, vol. 44, no. 11, pp. 885-897, 2003. 
[5] S. K. Ringer, K. Kalchofner, J. Boller, A. Fürst, and R. Bettschart-Wolfensberger, "A clinical comparison of two anaesthetic protocols using lidocaine or medetomidine in horses," Veterinary Anaesthesia and Analgesia, vol. 34, no. 4, pp. 257-268, 2007.

[6] L. Menard, "Tocolytic drugs to use in veterinary medicine," Canadian Veterinary Journal, vol. 25, pp. 389-393, 1984.

[7] S. A. Greene, "Protocols for anesthesia of cattle," Veterinary Clinics of North America-Food Animal Practice, vol. 19, no. 3, pp. 679-693, 2003.

[8] C. Peterbauer, P. M. Larenza, M. Knobloch et al., "Effects of a low dose infusion of racemic and S-ketamine on the nociceptive withdrawal reflex in standing ponies," Veterinary Anaesthesia and Analgesia, vol. 35, no. 5, pp. 414-423, 2008.

[9] H. Rohrbach, T. Korpivaara, U. Schatzmann, and C. Spadavecchia, "Comparison of the effects of the alpha-2 agonists detomidine, romifidine and xylazine on nociceptive withdrawal reflex and temporal summation in horses," Veterinary Anaesthesia and Analgesia, vol. 36, no. 4, pp. 384-395, 2009.

[10] S. Dehghani, A. Behbodikhah et al., "Clinical, haematological and biochemical effects of xylazine, ketamine and their combination in cattle and sheep," Veterinary Anaesthesia and Analgesia, vol. 18, pp. 123-128, 1991.

[11] C. L. Kerr, C. Windeyer, L. P. Bouré, K. K. Mirakhur, and W. McDonell, "Cardiopulmonary effects of administration of a combination solution of xylazine, guaifenesin, and ketamine or inhaled isoflurane in mechanically ventilated calves," American Journal of Veterinary Research, vol. 68, no. 12, pp. 1287-1293, 2007.

[12] E. J. Abrahamsen, "Ruminant field anesthesia," Veterinary Clinics of North America-Food Animal Practice, vol. 24, no. 3, pp. 429-441, 2008.

[13] R. Gehring, J. F. Coetzee, J. Tarus-Sang, and M. D. Apley, "Pharmacokinetics of ketamine and its metabolite norketamine administered at a sub-anesthetic dose together with xylazine to calves prior to castration," Journal of Veterinary Pharmacology and Therapeutics, vol. 32, no. 2, pp. 124-128, 2009.

[14] D. S. Hodgson, C. I. Dunlop, P. L. Chapman, and J. A. Smith, "Cardiopulmonary effects of xylazine and acepromazine in pregnant cows in late gestation," American Journal of Veterinary Research, vol. 63, no. 12, pp. 1695-1699, 2002.

[15] L. Luukkanen, T. Katila, and E. Koskinen, "Some effects of multiple administrations of detomidine during the last trimester of equine pregnancy," Equine Veterinary Journal, vol. 29, no. 5, pp. 400-403, 1997.

[16] C. A. Blaze, P. H. LeBlanc, and N. E. Robinson, "Effect of withholding feed on ventilation and the incidence of regurgitation during halothane anesthesia of adult cattle," American Journal of Veterinary Research, vol. 49, no. 12, pp. 2126-2129, 1988.

[17] P. Franci, E. A. Leece, and J. C. Brearley, "Post anaesthetic myopathy/neuropathy in horses undergoing magnetic resonance imaging compared to horses undergoing surgery," Equine Veterinary Journal, vol. 38, no. 6, pp. 497-501, 2006.

[18] W. A. Lindsay, W. McDonell, and W. Bignell, "Equine postanesthetic forelimb lameness: intracompartmental muscle pressure changes and biochemical patterns," American Journal of Veterinary Research, vol. 41, no. 12, pp. 1919-1924, 1980.

[19] J. L. Grandy, E. P. Steffey, D. S. Hodgson, and M. J. Woliner, "Arterial hypotention and the development of postanesthetic myopathy in halothane-anesthetized horses," American Journal of Veterinary Research, vol. 48, no. 2, pp. 192-197, 1987.
[20] W. A. Lindsay, G. M. Ribonson, D. B. Brunson, and L. J. Majors, "Induction of equine postanesthetic myositis after halothane-induced hypotension," American Journal of Veterinary Research, vol. 50, no. 3, pp. 404-410, 1989.

[21] R. B. Heath, J. Redder, T. Stashak, and R. Shaw, "Protecting and positioning the equine surgical patient," Veterinary Medicine, Small Animal Clinician, vol. 67, no. 11, pp. 12411245, 1972.

[22] P. Taylor and S. Young, "The effect of limb position on venous and compartmental pressure in the forelimb of ponies," Veterinary Anaesthesia and Analgesia, vol. 17, pp. 35-37, 1990.

[23] E. Steffey, "Inhalation anesthetics and gases," in Equine Anesthesia: Monitoring and Emergency Therapy, W. Muir and J. A. Hubbel, Eds., pp. 288-314, Elsevier, St. Louis, Mo, USA, 2009. 

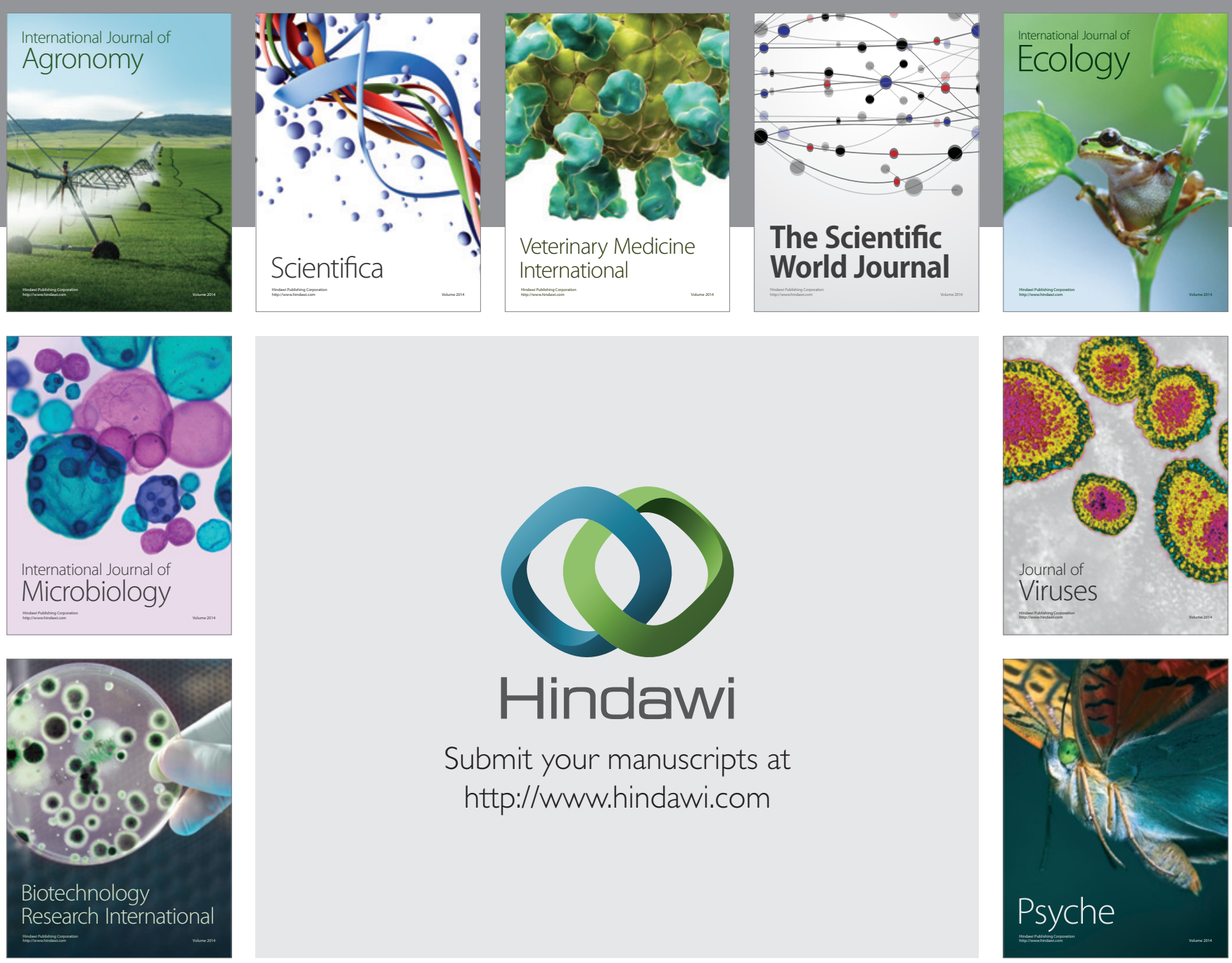

Submit your manuscripts at

http://www.hindawi.com
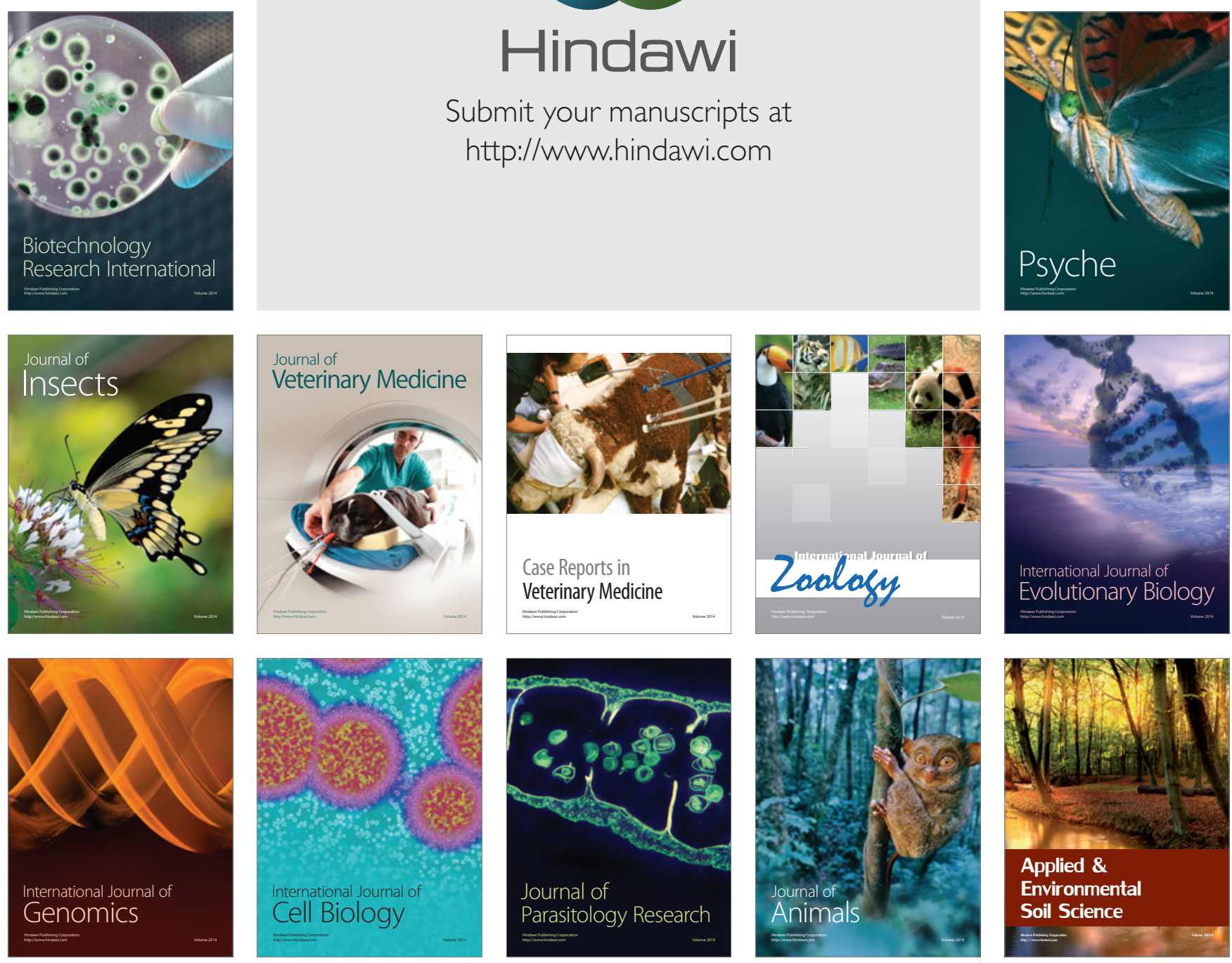